J. Perinat. Med. 16 (1988) 327

\title{
The ultrasonic Doppler fetal actocardiogram and its computer pro- cessing
}

\author{
Kazuo Maeda, Masato Tatsumura, Kazuhiko Nakajima, Takashi Ida, Naoki Nagata \\ and Yukihisa Minagawa
}

Department of Obstetrics and Gynecology, Tottori University School of Medicine, Yonago, Japan

\section{Introduction}

The movement of the fetus in utero is detected by the mother or alternatively by real-time ultrasonic B-mode scanning, but these are subjective. Objective recordings have been performed using tocodynamometry and other techniques, but these methods are not sufficiently sensitive. An objective and sensitive technique to record fetal movement has long been sought. The present report deals with a new ultrasonic Doppler method which gives an objective, sensitive and continuous recording of fetal movement of CTG chart $[1,2]$. We also report the results of the computer processing of these movement signals.

\section{Materials and methods}

The method is based on the detection of those ultrasonic Doppler signals which are of high amplitude and low frequency and are produced by fetal movements. The ultrasonic transducer is placed on the mother's abdomen overlying the fetal thorax at the point of detection of the fetal heart. Hence, the ultrasonic probe detects both fetal heart action and fetal movement at the same time. The Doppler frequency of the movement is lower, and the fetal heart signal is higher than 100 $\mathrm{Hz}$, when the ultrasound frequency is $2 \mathrm{MHz}$. These two signals are separated from each other when an appropriate band-pass filter is inserted into the circuit. The movement signal is detected with a $20-80 \mathrm{~Hz}$ band-pass filter when the ultrasound is at a level of $2 \mathrm{MHz}$. The fetal heart signal is detected with a low-cut filter of several hundred Hz. The Doppler movement signal is converted into deflections and recorded on the CTG chart.

\section{Curriculum vitae}

KazUo Maeda, DMS (PHD) was born in 1925 in Japan, studied medicine at Kyushu University, and has been Chairman and Professor of the Department of Obstetrics and Gynecology, Tottori University School of Medicine since 1968. His main interests include Obstetrics \& Gynecology, Perinatology, Medical En-

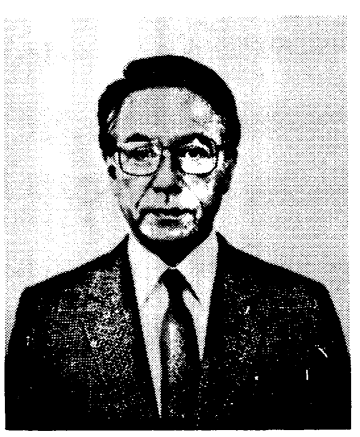

gineering and Ultrasound. President of the 4th Asia-Oceania Congress of Perinatology in 1986, the 3rd International Symposium "The Fetus as a Patient" in 1987 and the 2nd World Symposium "Computers in the Care of the Mother, Fetus and Newborn" in 1989.

Fetal heart rate (FHR) is recorded simultaneously with the movement signals.

The electrical output of the fetal actocardiograph, that is the record of fetal movement and FHR, is inserted into an analog-digital (AD) converter and a PC98XA computer. This displayed some of the original signals in the simple initial study, and also shows the results of advanced computer processing in the present one. Simple statistics of the amplitudes and intervals of the deflections, and also the histograms of the frequency and number of the intervals between deflections, and an envelope curve of the deflections was analysed. The fetuses were mainly in the 3rd trimester of pregnancy, and several normal as well as high-risk cases were studied. 


\section{Results}

\subsection{Visual analysis}

The characteristic deflection of the alternating rotational movements of the fetal trunk in the 3rd trimester of pregnancy similar to those visualized with a real-time B-mode device were seen. The burst-like grouping of fetal movement deflections which are associated with FHR accelerations is frequently observed with these fetal movements, namely in the active fetal state (figure 1). This active state is easily differentiated from the resting state of the fetus when neither fetal movement bursts are observed nor is FHR acceleration recorded. Fetal hiccups are not infrequently recorded and considered to be a physiological fetal phenomenon. Fetal well-being is determined by the frequent appearances of acceleration of the FHR which are concordant with fetal movement bursts.

The fetal actocardiogram has been used in the behavioural investigation of the fetus. The development of fetal activity was studied longitudinally during pregnancy, and the changes were noted in the number of movement bursts, the ratio of the FHR acceleration to the burst number, the amplitude of the acceleration accompanying the movement bursts and the pattern in each week of pregnancy during the 3rd trimester. Standard curves with normal ranges were obtained. For example, it was found that the number of fetal movement bursts increased after 22 weeks, and they were maximal at about 35 weeks of pregnancy. In twin pregnancy, the actocardiograms were recorded simultaneously on a single chart by employing 1 and $2 \mathrm{MHz}$ ultrasound. In some instances, the twins showed active states at the same time, though in most instances one fetus was active and other resting. The independence of the behaviour between the twins was estimated.

The actocardiogram also indicates fetal distress, particularly that due to hypoxia. High-risk cases including intrauterine growth retardation (IUGR), preeclampsia, etc., showed consistently lower values of fetal movement, sometimes at a value lower

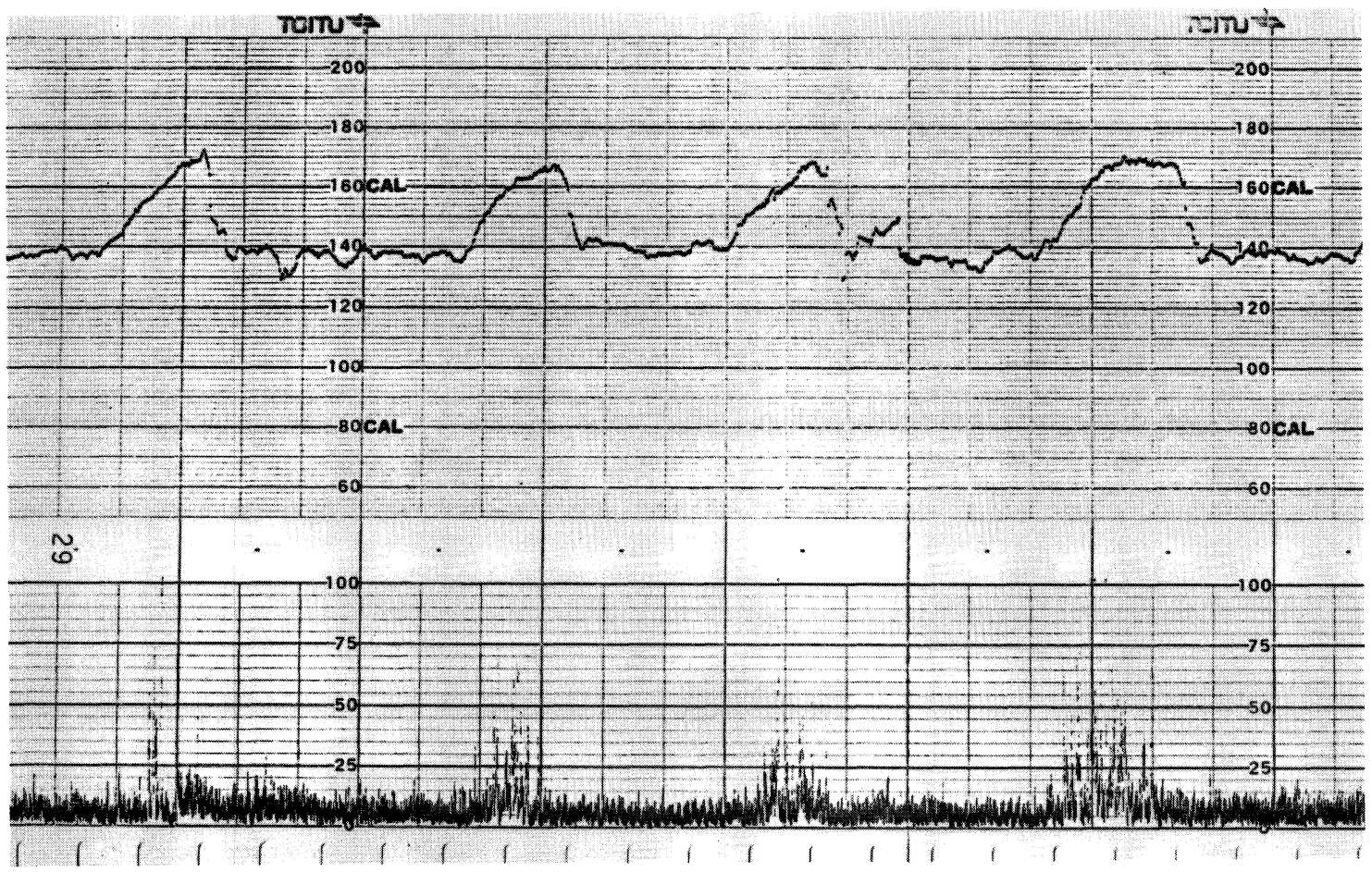

Figure 1. The actocardiogram shows the fetal active state. The upper line is the FHR, and the lower one is the record of fetal movement (actogram). Four FHR accelerations are concordant with the fetal movement bursts recorded in the actogram $(1 \mathrm{sec}=3 \mathrm{~cm})$. 
than the lowest range. Particularly, severe cases of IUGR who exhibited signs of fetal distress within a few days of the record, had shown highly abnormal values, especially in the amplitude of FHR acceleration which accompanies the movement burst. An IUGR case, for example, showed frequent fetal movement, however, no FHR acceleration was recorded. Two days later, severe FHR decelerations were demonstrated and fetal distress was diagnosed. A Caesarean section was done. Another case of IUGR at 31 weeks showed movement bursts but no FHR accleration. Instead, a long deceleration was noted on the FHR record. The fetus showed continuous bradycardia after the record was completed, and was delivered by Caesarean section. Hence fetal actocardiogram which shows no FHR acceleration when multiple movements bursts occur indicates that fetal distress is imminent. Obvious fetal distress which was observed during fetal hypoxia showed disappearance of the fetal movement signal. When this change was continuous and sufficiently long, and the FHR abnormality was clear, then the state was easily differentiated from a resting state of the fetus.

\subsection{Computer processing}

Although the value of the fetal actocardiogram has been confirmed from visual analysis, we planned to study the computerized analysis of the movement signal further to achieve more objective results. The actocardiographic signals were thus stored on a floppy disk and analysed with an offline technique. The primitive display of fetal movement deflections, uterine contractions, instanteneous movement rate and that of movement bursts demonstrated the active and resting states more clearly than was apparent on the original record. Simple statistics of the wave showed that the value for the amplitude, of the standard deviation and the coefficients of variation were increased in the active state. The burst intervals showed the same tendency as the amplitude.

The intervals between the deflections were analysed with 3-dimensional display of histograms showing the interval number. The histogram ranges were 25 or 50 intervals and 10 or $15 \mathrm{sec}$. Since signals which were lower than $0.1 \mathrm{~V}$ were regarded as noise, only voltage levels above $0.1 \mathrm{~V}$ were included in the histogram. The histogram of the active state showed a wide distribution of the peaks which persisted until high amplitude and

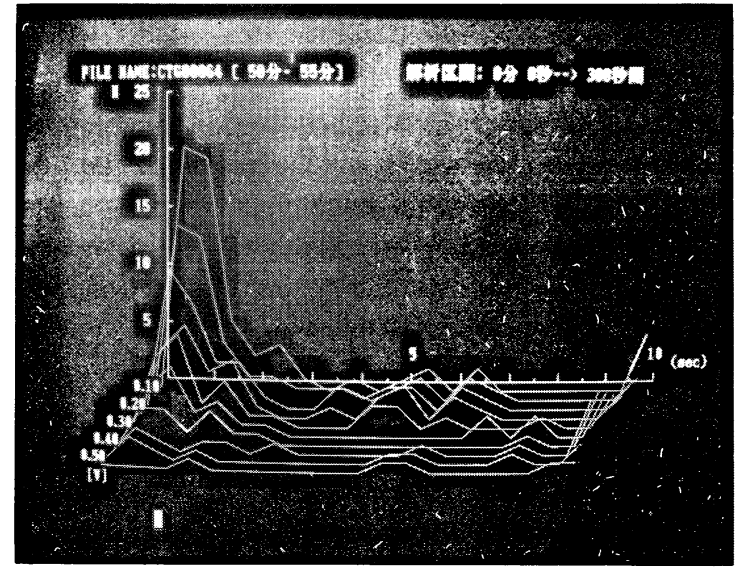

Figure 2. Three-dimensional histograms of the number of deflection intervals which were obtained by computer processing of the deflections. The ordinate is the deflection number of which the largest value is 25 in this figure. The abscissa shows the deflection interval for 10 secs, in $0.5 \mathrm{sec}$ steps. The 10 histograms were obtained with levels between 0.1 to $0.55 \mathrm{~V}$ for the deflection amplitude. The figure shows large peaks of high voltage and long interval in the active state. The resting state shows no peak at all in the histogram. The original display was in colour.

long intervals were reached (figure 2). In contrast, the resting state demonstrated very low amplitudes in the simple statistical analysis, and no peaks in the histogram.

Fetal breathing movement were confirmed using real-time B-mode scanning, and were also recorded on the actogram. The number of deflections was usually twice that of the number of breathing movements on the B-mode display. About $80 \%$ of the breathing was recognized on the actogram. This was characterized by moderately low, but uniform and frequent deflections. The interval histogram showed these peaks to be at low voltage steps, but the voltage was higher and there were more peaks than occured during the resting state. The peaks of the movement deflections were joined and an envelope curve was obtained by the use of computer processing. The envelope curve was concordant with the movement burst when the fetus was in the active state. No envelope curve was obtained in the fetal resting state, and the result was completely flat. Fetal breathing movements produced a flat but elevated line in the envelope, and the level was higher than it in the resting state. 
Summarizing the computer processing, we found that during the active fetal state there were the amplitude of the deflections as large as were the coefficients of variation in the amplitudes and of the intervals, multiple histographic peaks and clear envelope curves. During the fetal resting state the smallest values of all parameters were demonstrated, there were no peaks in the histograms, and no envelope curve. Fetal breathing showed higher values than during the resting state, and the interval histogram as well as the envelope showed a characteristic pattern.

\section{Conclusion}

The ultrasonic Doppler fetal actocardiogram is useful in studies of fetal behaviour, and computer processing is a promising technique for automatic recognizing different fetal behavioural states. Imminent fetal distress is clearly diagnosed in clinical management of late pregnancy and the labour.

This study was partly supported by the fund of the Ministry of Education (\#60870058).

\begin{abstract}
Gross fetal movement was detected using a lower frequency ultrasonic Doppler shift than that used in the study of fetal heart action. The movement signal was changed into deflection which was recorded on CTG chart simultaneously with the fetal heart rate (FHR), and was called the fetal actocardiogram. Visual analysis of the actocardiogram showed bursts of active fetal movements in the active fetal state which were concordant with acceleration of FHR. The analysis was useful in the study of fetal behavioural states. Imminent fetal distress produced a loss of FHR acceleration which was
\end{abstract}

accompanied by a burst of fetal movement, i.e. a true non-reactive state of the FHR. The output of the actocardiograph was analysed using a PC98XA computer with a simple statistics of deflection amplitude and interval, displayed as 3-dimensional histograms of the number and frequency, and the formation of the envelope curve of the deflections. The study demonstrated that it is possible to recognize fetal behavioural states automatically. This includes active and resting fetal states as well as fetal breathing movements.

Keywords: Actogram, computer, Doppler, fetal hypoxia, fetal movement, FHR, ultrasound.

\section{Zusammenfassung}

Das fetale Ultraschall-Doppler-Actocardiogramm und seine Verarbeitung per Computer

Obwohl die fetalen Bewegungen für die Beurteilung der Aktionen, des Verhaltens und des Wohlbefindens des Feten wichtig sind, wurde bis heute keine objektive und hinreichend sensitive Methode zur Messung fetaler Bewegungen verwandt. Das fetale Ultraschall-Doppler-Actocardiogramm ermittelt das durch die fetale Bewegung erzeugte niederfrequente Dopplersignal. Das Signal wird in elektrische Impulse mit dür CTG-Geräte passender Frequenzbreite umgewandelt. Die Bewegungen und der fetale Herzschlag werden gleichzeitig ermittelt und mittels Bandpaßfilter getrennt. Die gleichzeitige Ausgabe der Bewegungsimpulse und der FHF auf dem CTGDiagramm wird als fetales Actocardiogramm bezeichnet. Fetale Verhaltensformen wie Aktivität und Ruhe werden klar durch das Actocardiogramm erkannt. Die aktive Form ist charakterisiert durch dichte Salven von fetalen Bewegungsimpulsen und begleitende FHF-Akzelerationen. Der Ruhezustand zeigt weder Salven noch Akzelerationen. Die Entwicklung der fetalen Herzaktivität wurde im Verlauf der Schwangerschaft beobachtet, und für Parameter des fetalen Actocardiogramms wurden einige Normkurven mit Standardabweichungen abgeleitet.

Der drohende „fetal distress“, der ein lückenloses Monitoring des Feten erfordert, wird durch das Fehlen der FHF Akzelerationen, die normalerweise von fetalen Bewegungssalven begleitet sind, klar definiert. Die Computerverarbeitung wurde mit dem Ziel untersucht, über die visuelle Analyse des Actocardiogramms hinaus weitere objektive Ergebnisse zu erzielen. Die einfache Wiedergabe einiger Komponenten auf dem Bildschirm und die einfache Statistik der Bewegungszacken zeigten charakteristische Veränderungen zwischen den fetalen Aktivitätszuständen, der Ruhe und den Atembewegungen. Dreidimensionale Histogramme zeigten ausgeprägte Maxima bei fetaler Aktivität, keine Gipfel im Ruhezustand und Übergangsmuster bei fetaler Atmung. Die Hüllkurve, die durch Verbindung der Zackenspitzen entsteht, zeigte übereinstimmende Muster mit den fetalen Bewegungssalven. Die Hüllkurve erwies sich ebenso als nützlich bei der Unterscheidung der drei fetalen Bewegungsformen. Das völlig automatische Erkennen fetaler Verhaltensformen wird in Zukunft möglich sein.

Schlüsselwörter: Actogramm, Computer, Doppler, fetale Bewegungen, fetale Hypoxie, FHF, Ultraschall. 


\section{Résumé}

Actocardiogramme fotal par echographie doppler et traitement informatisé

Il n'a été utilisé de méthode objective pour enregistrer les mouvements fœtaux avec une sensibilité suffisante, bien que les mouvements fœtaux soient importants pour connaître l'activité, le comportement et également le bien-être du fœtus. L'actocardiogramme fœtal par échographie Doppler détecte le signal produit par le mouvement fœtal; il est composé de changement Doppler de basse fréquence approprié pour enregistrement CTG. Les mouvements et les battements cardiaques sont détectés de façon simultanée et séparés au moyen d'un filtre, puis les spikes des mouvements et le RCF sont enregistrés sur le CTG en même temps, l'actocardiogramme fotal est ainsi obtenu. Les états comportementaux de fœtus, qui comprennent des états d'activité et de repos, sont notés de façon claire par l'actocardiogramme. L'état d'activité est caractérisé par des slaves fréquentes de spikes de mouvements fœtaux et s'accompagne d'accélération du RCF. L'état de repos ne montre ni salves ni accélérations. On a étudié le développement de l'activité du fœetus tout au long de l'évolution de la grossesse et on a obtenu plusieurs courbes standards avec leurs variations normales pour les paramètres de l'actocardiogramme fœtal. La souffrance fœtale imminente, qui nécessite une surveillance rigoureuse du fœtus, est diagnostiquée de façon patente du fait de la disparition des accélérations du RCF qui s'accompagnent dans les cas normaux de salves de mouvements fotaux. On a étudié le traitement informatique avec l'objectif d'obtenir des résultats plus objectifs que ceux de l'analyse visuelle de l'actocardiogramme. Le seul affichage de plusieurs composantes et les seules statistiques des pics de mouvements montrent des modifications caractéristiques de l'état d'activité du fœtus, du repos et des mouvements respiratoires. Les histogrammes tri-dimensionels montrent des pics fréquents en cas d'état d'activité du fœtus, l'absence de pics au cours du repos, et des niveaux intermédiaires au cours des mouvements respiratoires. L'enveloppe obtenue en réunissant les sommets des spikes montre des modèles concordant avec les salves de mouvements fœtaux. L'enveloppe est également utile pour différencier les 3 états de mouvements fœtaux. Dans le futur la reconnaissance entièrement automatique des états comportementaux du fœtus sera possible.

Mots-clés: Actogramme, Doppler, hypoxie fœtale, mouvements fœtaux, ordinateur, RCF, ultrasons.

\section{References}

[1] Maeda K: Studies on new ultrasonic Doppler fetal actograph and continuous recording of fetal movements. Acta Obstet Gynecol Jpn 36 (1984) 280
[2] Maeda K, M Tatsumura, Y Minagawa, T Ohta, T IDA, N NAGATA: Evaluation of fetal development and well-being with ultrasonic doppler fetal actocardiogram. Zentbl Gynäkol 109 (1987) 873

K. Maeda, M.D.

Department of Obstetrics and Gynecology

Tottori University School of Medicine Nishimachi, Yonago 683, Japan 


\section{Willelm Friedrich}

\section{Vitamins}

$17 \mathrm{~cm}$ x $24 \mathrm{~cm}$. XII, 1062 pages. 1988. Hardcover. DM 380,-; approx. US \$225.00 ISBN 3110101447

A comprehensive, authoritative Handbook and reference source of all aspects of vitamins.

The book at a glance

- Complete and systematic overview of all water- and fat-soluble vitamins

- Introductory chapter presenting basic general information on the vitamins

- Numerous illustrations, formulas, tables, etc.

- Comprehensive and up-to-date bibliographic references at the end of each chapter

- Supplementary bibliography of publications that appeared subsequent to completion of the editorial work on the book

From the Contents

Introduction - Vitamin A and its Provitamins - Vitamin D - Vitamin E - Vitamin K. Thiamin (Vitamin $\mathrm{B}_{1}$, Aneurin) - Vitamin $\mathrm{B}_{2}$ : Riboflavin and its Bioactive Variants · Niacin: Nicotinic Acid, Nicotinamide, NAD (P) - Vitamin $B_{6} \cdot$ Folic Acid and Unconjugated Pteridines - Biotin - Pantothenic Acid - Vitamin $B_{12}$. Vitamin C · Literature Supplement $\cdot$ Subject Index

Potential audience

Biochemists, Biologists, Clinicians, Pharmacologists, Toxicologists, Physiologists, Pharmacists, Nutritionists, Organic and Analytical Chemists. Institutes, Libraries

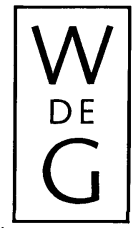

de Gruyter · Berlin · New York 